\title{
A origem da vida: uma análise sobre a natureza da ciência em um vídeo educativo do YouTube
}

Marinilde Tadeu Karat mtkarat@gmail.com

orcid.org/0000-0002-9444-9241 Universidade Federal de Santa Catarina (UFSC), Florianópolis, SC, Brasil

Patricia Montanari Giraldi patriciamgiraldi@gmail.com orcid.org/0000-0002-4283-1967 Universidade Federal de Santa Catarina (UFSC), Florianópolis, SC, Brasil

\section{RESUMO}

No presente artigo, tem-se como objetivo analisar quais são as visões sobre a natureza da ciência e a construção do conhecimento científico, presente em um vídeo educativo sobre a origem da vida, em um canal da plataforma YouTube Edu. Trata-se de um recorte da pesquisa de doutorado em andamento. Diante do aumento exponencial do uso de videoaulas por estudantes de ensino médio, considera-se importante entender como ocorre a circulação e o uso desses produtos educativos. A revisão de literatura apontou uma ausência de estudos sobre canais de audiovisuais que tivessem como referente o tema da origem da vida ou que investigassem como as controvérsias científicas circulam nesses canais de vídeo. Para o trabalho, utiliza-se como referencial teórico a epistemologia de Thomas Samuel Kuhn. Foi realizado um recorte dos primeiros dezesseis minutos da videoaula Origem da Vida, postado no Canal Biologia Total do professor Jubilut e se procedeu à decupagem (desconstrução) do vídeo, que corresponde a sua decomposição em seus elementos constitutivos. Os resultados das análises mostram que a videoaula trata o tema de forma muito semelhante àquela encontrada nos livros didáticos de biologia. O professor faz muitas afirmativas, não deixando espaço para reflexão nem para pensar em outras hipóteses, reduzindo o trabalho da ciência e dos cientistas. A análise da videoaula aponta alguns problemas a respeito do trabalho dos cientistas e sobre a natureza da ciência. Pode-se concluir que há uma predominância da concepção empíricoindutivista no vídeo analisado, o que ratifica outros trabalhos de pesquisa que analisaram as concepções de professores de ciências. Essas questões podem repercutir negativamente no ensino de ciências, principalmente com relação aos temas mais polêmicos e controversos.

PALAVRAS-CHAVE: Canais de vídeo. Natureza da ciência. História da ciência. Ensino de ciências. 


\section{INTRODUÇÃO}

Na última década, podemos observar que os audiovisuais estão sendo cada vez mais utilizados no ensino de ciências, muitas vezes integrados com outras mídias. Bévort e Belloni (2009, p. 1084), salientam que "a integração das TIC ${ }^{1}$ na escola, em todos os seus níveis, é fundamental porque estas técnicas já estão presentes na vida de todas as crianças e adolescentes".

Segundo Bruzzo (1999, p. 3), os estudantes passam boa parte do seu tempo, fora da escola entretidos no "mundo imagético". As pessoas passam mais tempo assistindo filmes, programas televisivos ou outras formas de imagens em movimento do que lendo textos escritos. Pelos audiovisuais, estudantes e professores "se informam e formam ideias a respeito das coisas do mundo e de como supostamente nos situamos nele." (BRUZZO, 1999, p. 3). Segundo Moran (2010, p. 13), educamos "quando aprendemos em todos os espaços que vivemos - na família, na escola, no trabalho, no lazer etc."

Em um artigo de revisão de literatura, Rezende Filho, Pereira e Vairo (2011) fizeram um levantamento sobre audiovisual no ensino de ciências, visto como mais um recurso pedagógico, uma ferramenta para a educação em ciências. Assim, o uso dos audiovisuais dentro da perspectiva instrumentalista não leva em "consideração um contexto escolar em que o aluno poderia ser visto como ator social, sujeito interativo, participante e colaborador do professor, e não como sujeito passivo". (REZENDE FILHO; PEREIRA; VAIRO, 2011, p. 201). Os autores também perceberam uma ausência de questionamento sobre a especificidade dos audiovisuais e sobre as relações entre sua concepção e utilização. Desse modo, fica implícita "a visão de que imagens são transparentes e permitem um acesso direto à realidade". (REZENDE FILHO; PEREIRA; VAIRO, 2011, p. 19). A noção de não transparência das imagens é importante para se pensar o ensino de ciências com uso de audiovisuais. Alguns autores defendem a importância da escola trabalhar contra a transparência da linguagem visual. Silva (2006, p. 71) defende a escola como "lugar de confronto e relação entre conhecimento cotidiano e conhecimento científico e lugar de formação de leitores de imagens na sociedade atual". Ao enfocar a relação entre imagens e realidade, Fischer (2012, p. 113) aponta que "a mídia não apenas veicula. Ela sobretudo constrói discursos ${ }^{2}$ e produz significados e sujeitos", embora ninguém possa garantir que o espectador vê "exatamente o que o realizador (ou produtor) espera/deseja que ele veja".

Mesmo os materiais audiovisuais construídos com uma intenção de retratar a realidade, como os documentários, normalmente associados a conteúdos considerados reais e científicos, são produtos resultantes de escolhas (planos de filmagem, iluminação, roteiros, sons...) feitas pelos profissionais envolvidos na sua produção. Assim, alguns pesquisadores têm apontado que o ideal seria que os professores agissem como mediadores dessas leituras, apontando controvérsias, interpretações diferentes, problemas não aprofundados, enfim, todas as questões que o documentário em questão não abordou" (NAPOLITANO, 2001, p. 31). No entanto, é comum que os professores tentem dar ênfase aos sentidos dominantes dentro da perspectiva da ciência, sem deixar espaço para que os estudantes reflitam sobre outros possíveis dizeres sobre ciência presentes nessas produções. Cassiani et al. (2012, p. 52) lembram que estes discursos científicos estão presentes nos "espaços discursivos sociais mais amplos 
(conversas, telejornais, revistas, noticiários etc.)" e que eles "não são homogêneos, pelo contrário, falam de diferentes ciências e tecnologias e de diferentes sentidos para os temas tecnocientíficos". (CASSIANI; GIRALDI; LINSINGEN, 2012, p. 52).

Não podemos ignorar que as novas tecnologias de informação e comunicação (TIC) estão presentes no cotidiano de alunos e professores e "funcionam - de modo desigual, real ou virtual - como agências de socialização, concorrendo com a escola e a família". (BÉVORT; BELLONI, 2009, p. 1084). Assim, acreditamos que a escola precisa repensar seu papel de mediadora na formação de leitores das novas tecnologias, fazendo com que os estudantes expressem suas compreensões e tenham um lugar mais crítico para as imagens em movimento.

Nesse contexto, os canais de videoaula do YouTube estão se tornando cada vez mais presentes na vida escolar dos estudantes brasileiros, sendo um fenômeno que não podemos ignorar. A popularização e a diversidade desses canais educacionais na internet e o seu enorme alcance (alguns canais de vídeo de ciência chegam a ter milhões de visualizações), nos fazem pensar que é necessário entender como ocorre a circulação e uso desses produtos educativos. O que e como as pessoas estão aprendendo por meio destes canais de vídeo? Estes vídeos funcionam como uma forma de divulgação científica, cumprindo um papel de educação informal? Estes canais de vídeo estariam mais voltados a uma espécie de treinamento para exames vestibulares e para conseguir uma boa pontuação no ENEM? Ou é possível aprender da forma como defendemos, um ensino crítico que contribua para a formação de sujeitos atuantes socialmente? Entendemos que essas questões são muito amplas e não temos a pretensão de respondê-las no contexto deste artigo. Trazemos apenas algumas pistas para respostas possíveis para essas perguntas.

\section{UM OLHAR SOBRE OS CANAIS DE VÍDEOS EDUCACIONAIS}

A plataforma de vídeos educacionais YouTube Educação - YouTube Edu foi lançada no ano de 2013 pelo Google Brasil, em parceria com a fundação Lemann, cujos objetivos são o desenvolvimento de projetos inovadores em educação e a realização de pesquisas para embasar políticas públicas no setor e formação de professores (FUNDAÇÃO LEMANN, 2018). Para que os professores produtores de vídeo possam incluir seus canais na plataforma, é necessário submetê-lo para a curadoria de uma equipe de professores coordenados pela Fundação. Essa curadoria tem o papel de avaliar o conteúdo dos vídeos quanto à adequação aos conceitos científicos, não levando em consideração a forma como o professor ensina (PORVIR, 2013).

São várias as promessas desta fundação a respeito do uso dos audiovisuais da plataforma YouTube Edu. Entre as principais propostas sobre os recursos audiovisuais da referida fundação estão a de que os audiovisuais passariam a ser não apenas complemento das aulas, mas também principal fonte de conteúdo, disponível para todos aqueles que tenham acesso à internet; poderiam ser usados como reforço de conteúdo ou para sua antecipação no momento em que o usuário achar mais conveniente; serviria como material extra para uso de professores; por terem uma linguagem mais lúdica, estimulariam o usuário a ter 
maior interesse nas ciências, que se refletiria em entender melhor conteúdos científicos e o aumento do aproveitamento dos estudantes em termos de notas em avaliações. (YOUTUBE EDU, 2018).

A propaganda a favor do uso dos canais de vídeo educacionais promete uma mudança de paradigma, uma revolução educacional. Mas será que estas videoaulas são tão inovadoras assim? O que mudou ou irá mudar, afinal, no ensino de ciências ao se utilizar estes canais de vídeo?

Ao realizarmos uma busca nas atas dos Encontros Nacionais de Pesquisa em Educação em Ciências (2011, 2013, 2015), nas edições eletrônicas dos principais periódicos da área de Ensino de Ciências e nos bancos de dissertação e tese do portal da Capes, encontramos as pesquisas de Rezende Filho et al. (2015), Silva e Pereira (2016) e Medina et al. (2015), que se dedicaram ao estudo dos canais de vídeo do YouTube.

A pesquisa de Rezende Filho et al. (2015) traz resultados de um estudo exploratório sobre a circulação e o uso de canais de vídeo para o ensino de ciências que se encontram disponíveis no YouTube. Como resultados deste estudo, os autores apontam a predominância dos modelos estéticos da tela-aula e videoaula e concepções tradicionais e comportamentalistas de educação. Os autores consideram importante mapear e entender o crescimento exponencial da oferta de videoaulas no YouTube, o que pode ajudar a compreender o seu significado diante do discurso que promete o aprimoramento e a revolução do ensino de ciências no Brasil. Como resultado das análises desenvolvidas na pesquisa citada, os autores indicam que o "conteúdo desses materiais não é automaticamente inovador ou revolucionário como advogam alguns desses canais, sobretudo os com fins comerciais, acerca do discurso em torno dessas produções". (REZENDE FILHO et al., 2015, p. 8).

Silva e Pereira (2016), em seu trabalho, investigaram quais são as fontes de pesquisa utilizadas por estudantes do ensino médio de uma escola pública para o estudo de biologia, física e química fora da sala de aula. Um dos resultados obtidos nesse estudo exploratório foi que $96 \%$ dos estudantes utiliza como fonte de pesquisa a internet. $\mathrm{O}$ acesso à internet é feito principalmente pelo celular (99\%) e pelo computador (84\%). Outro resultado foi que cerca de $70 \%$ destes estudantes costumam assistir a vídeos do YouTube para estudar as disciplinas das ciências da natureza. Para esses autores, diante do papel desempenhado pelos vídeos na formação dos estudantes, seriam necessárias mais pesquisas sobre o uso desse recurso no ensino das ciências naturais.

Medina et al. (2015) investigaram de forma exploratória, como estudantes de uma escola pública, recém-formados no ensino médio, fazem uso de videoaulas disponíveis no YouTube, em canais de vídeo selecionados pelos pesquisadores. Os resultados mostram que todos os alunos já assistiram às aulas virtuais, principalmente através do YouTube (96,5\%). De acordo com os resultados deste estudo, o principal objetivo no uso das videoaulas é o de aprender ou revisar os conteúdos a serem cobrados nas avaliações de seus professores. Outro resultado foi que os estudantes reconhecem que o material audiovisual é complementar às aulas presenciais, mas com a vantagem de poder parar o vídeo e retornar aos pontos ainda não bem compreendidos, o que não é possível em aulas presenciais. Dessa maneira, proporciona mais liberdade e respeito aos ritmos pessoais de compreensão da matéria. Os resultados da 
pesquisa mostram que os alunos "ainda creem que o número e a frequência das aulas a que assistiram é o fator responsável pela maior absorção dos conteúdos de sala de aula". (MEDINA et al., 2015, p. 7).

Segundo Medina et al. (2015), mesmo que as aulas dos canais de vídeo preferidos dos alunos sejam tradicionais e sem nenhuma inovação didática, ainda assim são recursos importantes no processo de ensino-aprendizagem. Outra declaração desses autores é que os alunos reconhecem como aulas os vídeos que possuem um mesmo arquétipo de sala de aula, com um professor em plano americano e um quadro em que ele apresenta a matéria como na própria sala de aula. Outros canais de vídeo como o Nerdologia, por não serem tradicionais e trazerem conteúdos transversais - de uma forma semelhante a do ENEM - não foram reconhecidos pelos alunos como aula-virtual. (MEDINA et al., 2015).

Mas, como os professores utilizam esses audiovisuais? Vidal (2010), em sua pesquisa de mestrado, analisou como os recursos audiovisuais são usados em sala de aula por professores de ciências e biologia recém-formados. 0 portal YouTube foi citado como principal meio de obtenção de vídeos para uso em sala de aula. Uma das vantagens do uso do portal que foram apontadas pelos entrevistados é que esses vídeos são curtos, o que possibilita seu uso no tempo de uma aula. Alguns professores entrevistados contam, inclusive, que fazem edições, cortes e alterações do áudio e outras intervenções no original como formas de adequar as obras ao espaço escolar e aos objetivos pretendidos na aula. (VIDAL, 2010).

Não encontramos nenhuma pesquisa que se dedicasse ao estudo dos discursos sobre ciência e tecnologia presentes nos audiovisuais educacionais do YouTube. Também não encontramos estudos sobre canais de audiovisual que tivessem como referente o tema da origem da vida ou que investigassem como as controvérsias científicas circulam nesses canais de vídeo.

Partindo do pressuposto de que, em um universo de milhares de videoaulas e dezenas de canais de vídeos, os discursos devam ser muito heterogêneos, nós colocamos algumas outras questões: que discursos sobre ciência e tecnologia estão circulando nestes espaços virtuais na internet? Quem são os professores produtores desses audiovisuais e qual é a sua visão de ensino de ciências? Essas questões fazem parte de uma pesquisa de doutorado que ainda está em fase inicial. Neste artigo, fizemos um recorte da referida pesquisa, buscando compreender quais são as visões sobre a natureza da ciência e sobre a construção do conhecimento científico presentes em uma videoaula sobre origem da vida, que é um tema controverso na ciência.

Acreditamos que é importante investigar essas questões e quem sabe, os resultados desses estudos possam ser úteis na formação inicial e continuada de professores de ciência, inclusive para aqueles que pretendem ser produtores de audiovisuais na internet.

\section{CAMINHOS DA ANÁLISE}

Neste artigo, apresentamos os resultados de um recorte de uma pesquisa de doutorado em andamento. Analisamos apenas uma videoaula da plataforma YouTube Edu, que tinha como referente o tema da origem da vida. Para fazer a 
seleção do vídeo a ser analisado, utilizamos as palavras-chave evolução e ensino de evolução e assistimos a vários vídeos sobre a temática da evolução biológica. Selecionamos o canal Biologia Total do professor Jubilut devido ao grande número de acessos (mais de um milhão de visualizações) e pelo fato desse professor estar em destaque na mídia televisiva, sendo muito popular entre os estudantes de ensino médio.

Para realização das análises tomamos como referência os trabalhos de análise fílmica propostas por Vanoye e Goliot-Leté (2012). Segundo esses autores, analisar um filme significa "decompô-lo em seus elementos constitutivos", de forma que a "desconstrução do filme equivale à descrição." (VANOYE; GOLIOT-LÉTÉ, 2012, p. 14). Assim, fizemos um recorte dos primeiros dezesseis minutos da videoaula Origem da Vida (JUBILUT, 2012) e procedemos à sua decupagem (desconstrução). Dessa forma, assistimos ao vídeo várias vezes a fim de identificar seus elementos constitutivos, tais como planos, sequências e cenas. Em seguida, fizemos Print Screen de cada um dos planos do vídeo e salvamos na extensão JPG no arquivo Paint do Windows. Colamos as imagens salvas no Word na ordem das sequências e construímos uma tabela com duas colunas: uma para as imagens (trilha de imagem) e outra para os sons (trilha de som). Após a decupagem, analisamos quais são as visões encontradas no audiovisual com relação à natureza da ciência e à construção dos conhecimentos científicos. Essa etapa das análises teve como base o referencial teórico de Thomas Samuel Kuhn, epistemólogo da ciência, utilizando especialmente os conceitos de paradigma, ciência normal, ciência extraordinária e revoluções científicas.

O vídeo Origem da Vida aborda um episódio de controvérsia, que faz parte da história da ciência. Dessa forma, o referencial escolhido é pertinente, pois Kuhn faz uma reconstrução da ciência e tem importantes contribuições para a compreensão acerca da atividade científica. Além disso, o pensamento de Kuhn favorece as discussões sobre as articulações entre ciência, sociedade e as revoluções científicas.

$\mathrm{Na}$ epistemologia de Kuhn, "'a ciência normal' significa a pesquisa firmemente baseada em uma ou mais realizações científicas passadas (paradigmas)." (MENDONÇA, 2012, p. 537). Os paradigmas ou exemplares orientam a investigação científica por meio de um consenso entre os membros de uma comunidade científica. No paradigma, há um compartilhamento de visões semelhantes sobre os fundamentos da prática científica, de forma que "homens cuja pesquisa está baseada em paradigmas compartilhados estão comprometidos com as mesmas regras e padrões para a prática científica". (KUHN, 2017, p. 72). Os conhecimentos científicos têm sua origem em problemas propostos pela comunidade científica, e as hipóteses que orientam a procura de dados e a resolução de problemas são formuladas no interior de um paradigma. Dessa forma, o paradigma teria a função de dogma na investigação científica. (KUHN, 2012).

Na visão de Kuhn, o progresso científico, no sentido de um aprofundamento do conhecimento, poderia acontecer de forma linear e cumulativa durante o período de ciência normal, dentro de um paradigma. Os períodos préparadigmáticos seriam o espaço das polêmicas, das controvérsias científicas, de confronto entre teorias rivais. Assim, no decorrer dos "períodos pré- 
paradigmáticos a ciência é praticada como ciência extraordinária, visto que em lugar de consenso há, agora, um profundo dissenso entre os cientistas". (KUHN, 2012, p. 18). No caso das revoluções científicas, o progresso científico seria não linear, com desenvolvimento científico não cumulativo. As mudanças de paradigma aconteceriam no caso de substituição total ou parcial de um paradigma por um novo, incompatível com o anterior (MENDONÇA, 2012).

\section{ALGUNS RESULTADOS E DISCUSSÕES}

Em um primeiro movimento de análise, identificamos que o cenário do vídeo não se modifica, o professor aparece sentado, com uma estante de livros atrás, falando o tempo todo e gesticulando muito. O modelo estético adotado na produção do vídeo é o da "vídeo-lição", que seria o equivalente em vídeo à aula expositiva tradicional, com uso de "vídeo-apoio", que teria a função de ilustrar o discurso do professor. (FERRÉS, 1996).

O conteúdo da videoaula também não é inovador ou revolucionário, como promete a propaganda da plataforma YouTube Edu. A videoaula trata o tema da origem da vida de forma bem objetiva e tem uma linguagem alegre e divertida, o que é um atrativo para o público jovem que segue os vídeos do canal Biologia Total. As videoaulas constituem um excelente recurso para estudar para as avaliações escolares, do ENEM e dos vestibulares, como mostram as pesquisas de Rezende Filho et al. (2015), Silva e Pereira (2016) e Medina et al. (2015). Apesar das características positivas, a videoaula analisada não deixa de ser uma aula tradicional e comportamentalista, assim como a maioria das videoaulas postadas na plataforma YouTube Edu.

Persiste na videoaula analisada a visão instrumentalista do audiovisual, visto como uma ferramenta para a educação em ciências. A interação entre locutor e audiência praticamente não existe na videoaula analisada. $O$ público pode deixar comentários, mas provavelmente eles não serão lidos e nem respondidos. Até a data da análise do vídeo tinham sido postados quase 4000 comentários sobre o vídeo Origem da Vida. Mesmo não havendo uma interação síncrona em uma videoaula, pesquisas como a de Medina et al. (2015) mostram que os estudantes consideram muito vantajoso a liberdade de poder parar o vídeo, voltar e repetir os trechos que não foram bem compreendidos ou assisti-los novamente. Isso se reflete em uma maior autonomia com relação à administração do seu tempo de estudo, acessando informações a qualquer hora por meio de celulares e de outros dispositivos móveis, de qualquer lugar que tenha acesso à internet.

O vídeo selecionado tem 30 minutos e traz o tema da origem da vida, questão antiga e que gerou debates intensos na segunda metade do século XIX. Questionava-se se seria possível ocorrer geração espontânea, ou seja, criar vida a partir da matéria bruta, inanimada. Tratava-se de um problema que envolvia questões políticas e religiosas e se tornou uma controvérsia científica na França nessa época. Atualmente, os pesquisadores baseados em conhecimentos de biologia, bioquímica e de teoria da evolução concordam que, com exceção das condições muito particulares da Terra primitiva, somente vida pode gerar outra vida.

Temos a tendência de supor que as concepções atuais sobre a origem da vida foram estabelecidas de forma rápida e decisiva, mas como explica Kuhn 
(2017), os intensos e profundos debates característicos do período préparadigmático não desaparecem completamente com o surgimento de um novo paradigma. Desse modo, assim como em muitas outras controvérsias científicas, como destacam Collins e Pinch (2010, p. 102):

[...] não foram nem os fatos nem os fundamentos, mas a morte e o peso dos números que venceram o ponto de vista minoritário; fatos e explicações, como sempre, foram ambíguos. Tampouco deveria pensar-se que foi apenas uma questão "dos que não querem ver". O triunfo mais decisivo de Pasteur, sua vitória sobre Felix Pouchet, conterrâneo e respeitado naturalista de Ruão, diante de uma comissão constituída pela Academia Francesa de Ciências, baseou-se na parcialidade dos seus membros e num grande golpe de sorte, em retrospectiva, podemos perceber o quanto Pasteur teve sorte.

O vídeo começa anunciando que a videoaula é sobre a origem do primeiro ser vivo na Terra. O professor inicia a aula falando sobre as crenças do criacionismo, de como a vida teria sido criada mediante o ato divino. Segue comentando sobre a panspermia, teoria que defendia a origem extraterrestre da vida na Terra, por meio de micro-organismos trazidos por meteoros e cometas. Depois, o professor apresenta algumas ideias sobre a teoria da abiogênese (geração espontânea) e comenta sobre como Von Helmont defendia a possibilidade de produzir ratos a partir de camisas suadas misturadas com grãos de trigo. O professor contrapõe com os experimentos de Redi, que demonstrou que as larvas de moscas não surgem espontaneamente a partir da carne podre. Segue fazendo a descrição dos experimentos de Pasteur e conclui afirmando que Pasteur provou que a geração espontânea não existe.

As teorias obsoletas, que já foram descartadas, são descritas no vídeo de forma anedótica, de maneira muito semelhante àquela utilizada pelos filósofos da ciência na década de 1960, como foi descrito por Kuhn (2012, p. 13): "a história reduzia-se a um inventário de anedotas ou de elogios aos feitos geniais dos cientistas do passado". Destacamos um fragmento da videoaula que exemplifica essa ideia:

[...] A abiogênese diz que a vida surge de matéria inanimada, é!!! Coisas que não são vivas formam seres vivos, que legal, que bacana! É, tú tá a fim de tirar sarro, nossa que idiota! Sim, tipo, existe uma força vital, uma energia na matéria inanimada que forma seres vivos. Desse copo aqui ó, shazan, surge um beija-flor! É malandro, a abiogênese acreditava nisso, tinha receita prá fazer rato, você juntava lá farinha de trigo, uma camisa usada por três dias, botava num porão e essa camisa tinha uma força vital que gerava ratos. Por favor né, nada a ver!

Encontramos na videoaula uma visão ingênua do trabalho científico, muito comum no cinema, nas histórias em quadrinhos e nos telejornais. Essa concepção empírico-indutivista e ateórica, é a da descoberta científica que "atribui a essência da atividade científica à experimentação". (GIL PÉREZ et al. 2001, p. 129). As investigações científicas são vistas de forma neutra, não levando em conta o "papel essencial das hipóteses como orientadoras da investigação, assim como dos corpos coerentes de conhecimentos (teorias) disponíveis, que orientam todo o processo". (GIL PÉREZ et al., 2001, p. 129). Abaixo um fragmento do vídeo no qual o professor Jubilut descreve o experimento de Redi: 
abiogênese aí meu, que viagem, nada a ver cara [...] eu vou fazer um experimentozinho e vou tentar destruir essa abiogênese.

Ao apresentar o trabalho de Redi na videoaula, este é enaltecido e fica a ideia de que os experimentos anteriores foram mal feitos, mal planejados. Pasteur é também enaltecido como cientista que conseguiu, por experimentos muito bem planejados, derrubar a teoria da geração espontânea, solucionando de forma definitiva este problema, como podemos observar no fragmento abaixo:

[...] aí o Pasteur mostrou isso prá galera e falou: tá vendo seus bobões como a abiogênese não existe? Ah, é verdade! Quer ver como agora os microorganismos vão começar a aparecer? Porque eles estão no ar! Ele foi e quebrou o pescoço de cisne e permitiu a entrada dos micro-organismos nesse suco nutritivo, e aí claro eles começaram a se desenvolver e apareceram aí. Esse experimento de Louis Pasteur foi importantíssimo, por quê? Porque ele conseguiu de vez acabar com a crença na abiogênese e deu força para o movimento novo que estava surgindo na época, chamado biogênese.

Apesar da videoaula, na maior parte do tempo, passar a ideia de que a teoria da biogênese substituiu de forma rápida e definitiva a teoria da abiogênese, sabemos que os debates e discussões de uma controvérsia científica não desaparecem completamente quando surge um novo paradigma. Essa resistência do período pré-paradigmático aparece em um dos trechos da videoaula:

[...] e o Redi ficou meio que naquela assim, consegui convencer os caras que a abiogênese era verdadeira, mas também não consegui, porque uma parte acreditou e outra parte continuou não acreditando.

Observamos na videoaula uma questão de desenvolvimento no tempo, com um silenciamento de um século de história. Os experimentos de Redi foram feitos em 1668, enquanto os experimentos do pescoço de cisne de Pasteur foram realizados em 1862. No vídeo fica a impressão de que os dois cientistas eram contemporâneos:

[...] eu vou fazer um experimentozinho e vou tentar destruir essa abiogênese, e foi o que o Redi fez e logo depois ele foi seguido por Louis Pasteur, que também fez um experimento do pescoço de cisne prá tentar destruir a abiogênese e dar força a uma nova corrente chamada de biogênese.

A possibilidade de observação de micro-organismos ao microscópio no século XVII favoreceu o renascimento da teoria da abiogênese. Novamente observamos um silenciamento de quase um século de história da ciência. A ideia que se mantém é que o ressurgimento do movimento da abiogênese aconteceu na mesma época dos experimentos de Redi, como verificamos no fragmento abaixo:

[...] só que Redi deu azar, porque logo depois eles descobriram o microscópio e descobriram os micro-organismos, bactérias, fungos e aí eles não acreditavam que esses micro-organismos tinham a capacidade de formar novos indivíduos e que para eles a abiogênese era verdadeira. 
A forma como o assunto foi apresentado na videoaula passa uma ideia de ciência evoluindo de forma linear, ficando a impressão de que esses pesquisadores defendiam ideias ingênuas e sem nenhum fundamento. À época de Kuhn, a história da ciência também era vista de modo mais popular, como um "processo contínuo, linear e invariavelmente progressivo, direcionado à busca da verdade e à superação dos erros, dos preconceitos e - eis a questão - dos dogmas do passado". (KUHN, 2012, p. 12). Essas inquietações foram decisivas para que Kuhn elaborasse o conceito de paradigma, muito importante na sua obra. Nessa época, Kuhn começa a se dar conta dos equívocos a respeito da história da ciência ensinada na sua formação como cientista. Kuhn (2017, p. 61) reforça que as crenças consideradas hoje obsoletas "foram produzidas pelos mesmos tipos de métodos e mantidas pelas mesmas razões que hoje conduzem ao conhecimento científico". Assim o historiador da ciência deve evitar olhar para a ciência do passado a partir da nossa perspectiva privilegiada, mas sim procurar "apresentar a integridade histórica daquela ciência a partir da sua própria época" e pensando que "teorias obsoletas não são em princípio acientíficas simplesmente porque foram descartadas". (KUHN, 2017, p. 62).

O professor Jubilut faz muitas afirmativas não deixando espaço para reflexão para pensar em outras hipóteses, reduzindo o trabalho da ciência e dos cientistas. A tentativa de resumir e fazer uma simplificação dos fatos acaba por apagar as controvérsias, os obstáculos, os problemas, desconsiderando toda a teia epistemológica das teorias científicas. Abaixo destacamos um fragmento do vídeo:

[...] o que é que o Pasteur fez? O Pasteur sabia que os micro-organismos, eles estavam no ar e que claro, que eles não iriam surgir pela abiogênese. Então o Louis Pasteur, com o seu experimento do pescoço de cisne deu aquela força a biogênese. Vai, agora é a sua vez! A abiogênese dizia que um ser vivo surge de um não ser vivo, a biogênese diz que um ser vivo surge de outro ser vivo. E o Pasteur começou a defender essa corrente, o cara abalando, se achando pop star.

Sobre as visões deformadas que alguns professores têm sobre o trabalho científico e que acabam por refletir negativamente no ensino de ciências, Gil Pérez et al. (2001, p. 131) mencionam que a "visão aproblemática e a-histórica (portanto, dogmática e fechada): transmitem-se os conhecimentos já elaborados, sem mostrar os problemas que Ihe deram origem, qual foi sua evolução, as dificuldades encontradas etc."

A videoaula desconsidera o longo debate que existiu entre Pasteur e Pouchet na segunda metade do século XIX. A controvérsia entre Pasteur e Pouchet é apagada, assim como o fato desse embate ter ocorrido coincidentemente com a divulgação da teoria de Charles Darwin sobre a origem das espécies em 1859. Pouchet foi um médico e naturalista que realizou pesquisas favoráveis à geração espontânea de organismos microscópicos e que teve a publicação dos seus trabalhos em 1856. Os experimentos de Pasteur e de Pouchet foram ambos muito bem feitos e rigorosos. Embora nenhum deles tenha convencido o outro, "seus trabalhos não eram meras opiniões baseadas em crenças pré-concebidas". (MARTINS, 2009, p. 80).

Segundo Gil Pérez (2001), uma visão deformada muito frequente entre os professores é a de que os conhecimentos científicos crescem de forma linear e 
cumulativa, sem se preocupar em mostrar como eles foram alcançados, de modo a apagar as controvérsias e as mudanças complexas nas teorias. Na verdade, essas visões deformadas também estão presentes entre autores de materiais didáticos, entre cientistas e na população em geral.

Para Kuhn (2012, p. 201), esse processo de mudança "não pode ser comparado com um processo linear no qual tijolos são adicionados um a um visando à conclusão de um único edifício". Para Martins (2009, p. 83),

[...] Toda a concepção epistemológica e histórica que está por trás dessas narrativas é equivocada, transmitindo uma visão ingênua e errada sobre como a ciência se desenvolve e como ela é fundamentada. Por fim, o debate sobre geração espontânea é apresentado como algo isolado, não se mostrando sua conexão com outras discussões científicas importantes, como a teoria da evolução no século XIX.

A videoaula do professor Jubilut silencia aspectos importantes sobre a natureza da ciência e sobre as controvérsias científicas, como foi o caso do debate sobre a geração espontânea. Segundo Martins (2009, p. 91),

Uma controvérsia científica é uma disputa pública a respeito de temas científicos, envolvendo participantes que têm opiniões discordantes e que tentam defendê-las utilizando argumentos que, pelo menos em parte, são baseados em observações, experimentos e argumentos racionais.

A história da ciência nos mostra que o sucesso de Pasteur não se deu unicamente pelos seus experimentos brilhantes, mas também por outros fatores como interesses políticos e religiosos. Na França daquela época, de acordo com Martins (2009, p. 73), "as ideias de geração espontânea e de origem das espécies (considerados como associados) eram consideradas perigosas, pois eram vistas como fazendo parte de uma ideologia materialista".

Para Gil Pérez et al. (2001, p. 133), quando a ciência é apresentada de forma descontextualizada, socialmente neutra e sem levar em consideração as relações entre ciência, tecnologia e sociedade (CTS), acaba proporcionando uma "imagem deformada dos cientistas como seres 'acima do bem e do mal', fechados em torres de marfim e alheios à necessidade de fazer opções".

Collins e Pinch (2010, p. 102) relatam que Pasteur esmagou a oposição por meio de "manobras políticas", "pela ridicularização e pelo fato de Pasteur ter atraído fazendeiros, cervejeiros e médicos para sua causa".

A Academia de Ciências de Paris ofereceu um prêmio para o melhor trabalho sobre a questão da geração espontânea (1860). Pasteur dedicou-se a essa questão, mas não refutou e nem tentou refazer os estudos de Pouchet. Repetiu experimentos já publicados com resultados contrários à geração espontânea e submeteu seus estudos à comissão julgadora. Pouchet e mais dois pesquisadores retiraram seus trabalhos ao notarem que a comissão só tinha membros declaradamente contrários à geração espontânea. (GEISON, 2002). O único candidato foi Pasteur, que recebeu o prêmio em 1862. Pasteur cometeu uma violação grave, por não ter falseado ${ }^{3}$ os experimentos de Pouchet, mas a comissão julgadora não percebeu tal violação, pelo contrário, elogiaram o rigor dos seus experimentos. Na questão da geração espontânea, Pasteur fez uso de suas preconcepções, preconceitos, ideologia e de sua fé religiosa, de forma que: 
Especialmente durante a década de 1860, quando a teoria evolucionista e a geração espontânea eram vistas como parte de uma ameaça maior à ordem estabelecida, Pasteur claramente ansiou por destruir essa doutrina por simples motivos políticos. (GEISON, 2002, p. 159).

O debate sobre geração espontânea poderia ter tido um outro desfecho se Pasteur tivesse reproduzido rigorosamente os experimentos de Pouchet. $\mathrm{Na}$ época, Pasteur já tinha conhecimento de que certos micro-organismos (inclusive as infusões de feno) tinham resistência ao calor e que essa resistência aumentava nos meios alcalinos, o que poderia explicar supostos casos de geração espontânea. (GEISON, 2002). Graças aos intensos e contínuos trabalhos experimentais fora da França, onde os cientistas estavam mais distantes das motivações políticas da geração espontânea, "ficou claro, no início da década de 1870, que a vida microbiana de fato aparecia com frequência nas infusões de feno fervido". (GEISON, 2002, p. 156).

$\mathrm{Na}$ videoaula, o professor afirma que Pasteur provou que a geração espontânea não existe, mas é interessante considerar que mesmo que Pasteur tivesse reproduzido os experimentos de Pouchet, ele não poderia ter provado que a geração espontânea não existe.

\section{CONSIDERAÇÕES FINAIS}

A análise da videoaula aponta alguns problemas a respeito do trabalho dos cientistas e sobre a natureza da ciência. Podemos observar a predominância da concepção empírico indutivista e a-teórica, o que concorda com outros trabalhos de pesquisa que analisaram as concepções de professores de ciências. (GIL PÉREZ et al., 2001; SCHEID et al., 2007). Essas questões podem repercutir negativamente no ensino de ciências, principalmente com relação aos temas mais polêmicos e controversos.

Concordamos que a história da ciência deve ser inserida nos currículos escolares e que ela tem benefícios para a formação dos alunos, tais como o desenvolvimento do pensamento crítico e uma melhor compreensão sobre a natureza da ciência. No entanto, é necessário tomar os devidos cuidados sobre que história da ciência será contada. A análise da videoaula constatou a presença dos mesmos problemas encontrados por Martins $(1998,2009)$ em livros didáticos de Biologia, com uma excessiva simplificação e desenvolvimento linear da história da ciência, a não consideração do contexto sociohistórico, a omissão de informações relevantes que poderiam aguçar o senso crítico dos alunos, a neutralidade da ciência e o apagamento das controvérsias. Os episódios históricos envolvendo a temática da origem da vida poderiam ter sido trabalhados de forma mais adequada na videoaula do professor Jubilut, contribuindo para uma melhor compreensão do funcionamento da ciência. Martins (2009, p. 95), por exemplo, sugere que a descrição da controvérsia entre Pasteur e Pouchet seja apresentada baseada em "estudos aprofundados da documentação existente sobre o período" e que se afaste da pseudo-história.

Para Kuhn (2017), existe um período chamado de ciência normal, no qual a pesquisa está baseada em uma ou mais realizações científicas passadas (paradigmas), relatadas em manuais científicos elementares e avançados. $\mathrm{Na}$ educação científica, os estudantes teriam uma iniciação científica dogmática e 
acrítica e seriam pouco encorajados a ler os textos originais dos cientistas. Os manuais científicos acabariam, de certa forma, por apagar a historicidade do conhecimento científico. Percebemos que essa característica da educação científica também se repete no ensino fundamental e médio através do uso do livro didático. Para Ramos (2010, p. 48), "há mecanismos discursivos de regulação dos sentidos para as práticas científicas que se repetem mesmo em níveis escolares que não visam à formação de cientistas, como no ensino básico".

A história da ciência que é mostrada na videoaula, não difere muito daquela que Kuhn descreve a respeito da sua própria formação científica, com visões distorcidas da ciência, permeada por anedotas ou "elogios aos feitos geniais dos cientistas do passado". (KUHN, 2012, p. 13). As concepções equivocadas encontradas na videoaula também podem ser encontradas em textos de divulgação científica e em outras mídias populares, fazendo parte do universo simbólico de professores e estudantes. Segundo Fernandez et al. (2002), a imagem que um professor faz da ciência não difere muito daquela expressa por qualquer cidadão.

É preciso investir na formação dos professores, pois, embora a maioria concorde com a importância de trabalhar com a história da ciência em sala de aula, muitos professores têm concepções epistemológicas equivocadas. (GIL PÉREZ et al., 2001; SCHEID et al., 2007; MARTINS, 2015). Existe uma lacuna na formação inicial e continuada de professores das áreas científicas, de forma que "raramente apresentam uma base epistemológica que propicie uma reflexão sobre a natureza da ciência". (SCHEID et al., 2007, p. 168). Assim, os professores produtores de videoaulas podem acabar repetindo os mesmos problemas encontrados nos livros didáticos e nas mídias populares. Conforme apontam as pesquisas de Corrêa et al. (2010), uma forma interessante de trabalhar com futuros professores de biologia, para que estes tenham uma concepção mais adequada sobre a natureza da ciência, seria utilizar "episódios históricos, tendo por base a leitura de textos originais e fontes secundárias confiáveis". (CORRÊA et al., 2010, p. 223).

Os audiovisuais fazem parte do cotidiano de professores e alunos (e da população em geral) e são utilizados com objetivos que vão além do entretenimento. Considerando o grande potencial educativo dos audiovisuais, tanto na educação formal quanto na educação informal, e lembrando da não transparência das imagens, é importante pensar na formação de leitores mais críticos dos audiovisuais. Nas escolas, ao utilizar audiovisuais nos seus processos de ensino, os professores poderiam atuar como mediadores, levantando outras questões que não foram abordadas no vídeo. Dessa maneira, eles discutiriam as possíveis controvérsias científicas e abririam espaço para que os estudantes pensassem outros possíveis dizeres sobre ciência, evitando dar ênfase apenas aos sentidos dominantes, dentro da perspectiva da ciência.

Vidal (2010) mostrou que professores costumam utilizar vídeos curtos do YouTube em processos de ensino, inclusive fazendo edições no material original como forma de adequá-los aos objetivos que pretendem alcançar nas suas aulas. No entanto, existe o risco de alguns professores utilizarem os audiovisuais de forma acrítica, sem muita reflexão, repetindo visões ingênuas da ciência, muito comuns nas mídias populares, assim como observamos no vídeo Origem da vida. A forma como os professores utilizam os audiovisuais em sala de aula pode ter 
relação com as leituras que esses professores fazem dos audiovisuais, por isso consideramos importante investir na formação de professores leitores dos audiovisuais.

Os resultados da análise da videoaula são parte de uma pesquisa que ainda está no início, mas apontam para a importância do aprofundamento dos estudos dos canais de vídeo. É importante entender quem são os produtores das videoaulas, quais são os discursos sobre ciência e tecnologia produzidos e quais são os modos de circulação em todos os níveis de ensino de ciências. 


\title{
The origin of life: an analysis of the nature of science in an YouTube educational video
}

\begin{abstract}
This article aims to analyze what are the views on the nature of Science and the construction of scientific knowledge are present in an educational video about the Origin of Life, in a channel of the educational video platform YouTube Edu, constituting a clipping of a PhD research in progress. Given the exponential increase in the use of video lessons by high school students, it is important to understand how the circulation and use of these educational products occurs. The literature review pointed to an absence of studies on audiovisual channels that had as their reference the origin of life theme or that investigated how scientific controversies circulate in these video channels. The work uses as theoretical reference the epistemology of Thomas Samuel Kuhn (2017). We made a cut of the first sixteen minutes of the video lesson Origin of Life (ORIGEM, 2012), posted on the Total Biology Channel, by Professor Jubilut and proceeded to decoup (deconstruction) the video. Decoupage corresponds to a decomposition of the video into its constitutive elements, so that the "deconstruction of the film is equivalent to the description." (VANOYE; GOLIOT-LÉTÉ, 2012, p. 14). The results of the analysis show that the video lecture treats the subject very similar to that found in the biology textbooks. The teacher makes many statements, leaving no room for reflection, to think other hypotheses, reducing the work of Science and scientists. Video lesson analysis points out some problems about the work of scientists and the nature of Science. We could conclude that there is a predominance of the inductivist empirical conception in the analyzed video, which agrees with other research Works that analyzed the conceptions of Science teachers (GIL- PÉREZ et al.2001; SCHEID et al., 2007). These questions can have a negative impact on science education, especially regarding the most controversial, controversial topics.
\end{abstract}

KEYWORDS: Video channels. Nature of Science. History of Science. Science teaching. 


\section{NOTAS}

1. Tecnologias de informação e comunicação (TIC) ou Tecnologias Digitais de Informação e Comunicação (TDIC).

2. Segundo Orlandi (2013, p. 21), "discurso é efeito de sentidos entre locutores".

3. A falseabilidade, proposta por Karl Popper pressupõe que "uma hipótese é falsificável se existe uma proposição de observação ou um conjunto delas logicamente possíveis que são inconsistentes com ela, isto é, que, se estabelecidas como verdadeiras, falsificariam a hipótese". (CHALMERS, 1993, p. 56).

\section{REFERÊNCIAS}

BÉVORT, E.; BELLONI, M. L. Mídia-Educação: conceitos, história e perspectivas. Revista Educação e Sociedade v. 30, n. 109, p. 1081- 1102, set./dez., 2009. Disponível em: http://www.scielo.br/pdf/es/v30n109/v30n109a08.pdf. Acesso em: 19 jan. 2019.

BRUZZO, C. Filmes e escola: isto funciona? Ciência \& Ensino, n. 6, 1999. Disponível em: http://200.133.218.118:3535/ojs/index.php/cienciaeensino/article/view/50/49. Acesso em: 19 jan. 2019.

CASSIANI, S.; GIRALDI, P. M.; LINSINGEN, I. É possível propor a formação de leitores nas disciplinas de Ciências Naturais? Contribuições da análise de discurso para a educação em ciências. Educação: Teoria e Prática, v. 22, n 40, maio/ago., 2012. Disponível em:

https://www.periodicos.rc.biblioteca.unesp.br/index.php/educacao/article/view/ 6270. Acesso em: 19 jan. 2019.

CHALMERS, A. F. O que é ciência afinal? São Paulo: Editora Brasiliense, 1993.

COLLINS, H.; PINCH, T. O Golem: o que você deveria saber sobre ciência. 2. ed. Belo Horizonte, Minas Gerais: Fabrefactum Editora, 2010.

CORRÊA, A. L.; ARAÚJO, E. N. N.; MEGLHIORATTI, F. A.; CALDEIRA, A. M. A. História e filosofia da biologia como ferramenta no ensino da evolução na formação inicial de professores de Biologia. Filosofia e História da Biologia, v. 5, n. 2, p. 217-237, 2010. Disponível em: http://www.abfhib.org/FHB/FHB-052/FHB-5-2-12-Andre-Correa-Elaine-Araujo-Fernanda-MegIhioratti-AnaCaldeira.pdf. Acesso em: 19 jan. 2019.

FERNANDEZ, I.; GIL, D.; CARRASCOSA, J.; CACHAPUZ, A. Visiones deformadas de la ciência transmitidas por la enseñanza. Enseñanza de las ciências, v. 20, n. 3, p. 477-488, 2002. Disponível em: https://ddd.uab.cat/pub/edlc/02124521v20n3/02124521v20n3p477.pdf. Acesso em: 19 jan. 2019. 
FERRÉS, J. Vídeo e Educação. Belo Horizonte: Autêntica Editora, 1996.

FISCHER, R. M. B. Trabalhar com Foucault: arqueologia de uma paixão. Belo Horizonte, MG: Autêntica Editora, 2012.

FUNDAÇÃOLEMANN. Fundação Lemann: formar, 2018. Pinheiros, SP. Disponível em: https://fundacaolemann.org.br/projetos/formar. Acesso em: 19 jan. 2019.

GEISON, G. A ciência particular de Louis Pasteur. Rio de Janeiro: Fiocruz:

Contraponto, 2002.

GIL PÉREZ, D. G.; MONTORO, I. F.; ALÍS, J. C.; CACHAPUZ, A.; PRAIA, J. Para uma imagem não deformada do trabalho científico. Ciência e Educação, v. 7, n. 2, p. 125-153, 2001. Disponível em: http://www.scielo.br/pdf/ciedu/v7n2/01.pdf. Acesso em: 19 jan. 2019.

JUBILUT, P. Origem da vida. Biologia Total com Prof. Jubilut. 30m5s, 6 mar. 2012. Disponível em: https://www.youtube.com/watch?v=wrPcm5FseGo. Acesso em: 19 jan. 2019.

KUHN, T. S. A estrutura das revoluções científicas. 13. ed. São Paulo, SP: Editora Perspectiva, 2017.

KUHN, T. S. A função do dogma na investigação científica. Barra, E. S. O. (org.); Deus, J. D. de (trad.). Curitiba: UFPR, SCHILA 2012.

MARTINS, A. F. P. Natureza da ciência no ensino de ciências: uma proposta baseada em "temas" e "questões". Caderno Brasileiro de Ensino de Física, v. 32, n. 3, p. 703-737, dez. 2015. Disponível em:

https://periodicos.ufsc.br/index.php/fisica/article/view/2175-

7941.2015v32n3p703/30644. Acesso em: 19 jan. 2019.

MARTINS, L. A. P. A história da ciência e o ensino da biologia. Ciência e Ensino, n. 5, p. 18-21, 1998. Disponível em:

http://www.educadores.diaadia.pr.gov.br/arquivos/File/fevereiro2013/ciencias artigos/historia ciencia.pdf. Acesso em: 19 jan. 2019.

MARTINS, L. A. P. Pasteur e a geração espontânea: uma história equivocada. Filosofia e História da Biologia, v. 4, p. 65-100, 2009. Disponível em: http://www.abfhib.org/FHB/FHB-04/FHB-v04-03-Lilian-Martins.pdf. Acesso em: 19 jan. 2019.

MEDINA, M. N.; BRAGA, M.; REGO, S. C. R. Ensinar Ciências para alunos do século XXI: o uso de videoaulas de ciências da natureza por alunos do ensino médio de uma escola pública federal. In: ENCONTRO NACIONAL DE PESQUISA EM EDUCAÇÃO EM CIÊNCIAS, Águas de Lindóia, 2015. Atas do X ENCONTRO NACIONAL DE PESQUISA EM EDUCAÇÃO EM CIÊNCIAS. Disponível em: 
http://www.abrapecnet.org.br/enpec/x-

enpec/anais2015/busca.htm?query=Ensinar+Ci\%EAncias+para+alunos+do+s\%E9c ulo+XXI\%3A+o+uso+de+videoaulas+de+ci\%EAncias+da+natureza+por+alunos+do tensino+m\%E9dio+de+uma+escola+p\%FAblica+federal. Acesso em: 19 jan. 2019.

MENDONÇA, A. L. O. O legado de Thomas Kuhn após cinquenta anos. Scientiae Studia, v. 10, n. 3, 2012, p. 535-60. Disponível em: < http://www.scielo.br/pdf/ss/v10n3/06.pdf. Acesso em: 19 jan. 2019.

MORAN, J. M. Ensino e aprendizagem inovadores com tecnologias audiovisuais e telemáticas. In: MORAN, J. M.; MASETTO, M. T.; BEHRENS, M. A. Novas tecnologias e mediação pedagógica. 17 ed. São Paulo: Ed. Papirus, 2010, p. 1166.

NAPOLITANO, M. Como usar o cinema na sala de aula. São Paulo: Editora Contexto, 2011.

ORLANDI, E. P. Análise de Discurso: princípios e procedimentos. 5. ed. Campinas, SP: Pontes, 2013.

PORVIR. Google lança novo canal YouTube Edu. 21 nov. 2013. Disponível em: http://porvir.org/google-lanca-novo-canal-youtube/. Acesso em: 19 jan. 2019.

RAMOS, M. B. Na pauta das aulas de ciências: discussão de controvérsias científicas na televisão. Tese (doutorado em Ciências), Instituto de Geociências, Pós-graduação em Ensino e História de Ciências da Terra, Universidade Estadual de Campinas (UNICAMP), São Paulo, 2010. Disponível em:

http://repositorio.unicamp.br/bitstream/REPOSIP/286776/1/Ramos MarianaBra sil D.pdf. Acesso em: 19 jan. 2019.

REZENDE FILHO, L. A. C.; PEREIRA, M. V.; VAIRO, A. C. Recursos audiovisuais como temática de pesquisa em periódicos brasileiros de Educação em Ciências. Revista Brasileira de Pesquisa em Educação em Ciências, v. 11, n. 2, 2011. Disponível em: https://periodicos.ufmg.br/index.php/rbpec/article/view/4202/2767. Acesso em: 19 jan. 2019.

REZENDE FILHO, L. A. C.; SÁ, M. B.; PEREIRA, M. V.; BASTOS, W. G.; PASTOR JÚNIOR, A. A.; PINHEIRO, A. R. Canais de vídeo para ensino de ciências: um estudo exploratório. In: ENCONTRO NACIONAL DE PESQUISA EM EDUCAÇÃO EM CIÊNCIAS, Águas de Lindóia, 2015. Atas do X ENCONTRO NACIONAL DE PESQUISA EM EDUCAÇÃO EM CIÊNCIAS. Disponível em:

http://www.abrapecnet.org.br/enpec/x-enpec/anais2015/resumos/R1631-1.PDF. Acesso em 19: jan. 2019.

SCHEID, N. M. J.; FERRARI, N.; DELIZOICOV, D. Concepções sobre a natureza da ciência num curso de ciências biológicas: imagens que dificultam a educação científica. Investigações em Ensino de Ciências, v. 12, n. 2, 2007. Disponível em: https://www.if.ufrgs.br/cref/ojs/index.php/ienci/article/view/470/272. Acesso em: 19 jan. 2019. 
SILVA, H. C. Lendo imagens na educação científica: construção e realidade. PróPosições, v. 1, n. 1, jan./abr. 2006. Disponível em: https://www.fe.unicamp.br/pffe/publicacao/2346/49 dossie silvahc.pdf. Acesso em: 19 jan. 2019.

SILVA, M. J.; PEREIRA, M. V. O uso de vídeos por estudantes de ensino médio no estudo das ciências da natureza. In: SIMPÓSIO NACIONAL DE ENSINO DE CIÊNCIAS E TECNOLOGIA, Ponta Grossa, 2016. Atas do V SIMPÓSIO NACIONAL DE ENSINO DE CIÊNCIAS E TECNOLOGIA, UTFPR, Ponta Grossa, PR, 2016. Disponível em: http://www.sinect.com.br/2016/selecionados.php. Acesso em: 19 jan. 2019.

YOUTUBE EDU: Conheça a história do projeto. 2018. Disponível em:

https://www.youtube.com/watch?v=YdpWbofz8T0. Acesso em: 19 jan. 2019.

VANOYE, F.; GOLIOT-LÉTÉ, A. Ensaio sobre análise fílmica. Papirus Editora, 2012.

VIDAL, F. L. K. Recursos audiovisuais na prática docente de professores de ciências formados pela UFRJ, 2010. Dissertação (Mestrado em Educação em Ciências e Saúde) - Programa de Pós-Graduação em Educação em Ciências e Saúde, Núcleo de Tecnologia Educacional para a Saúde, Universidade Federal do Rio de Janeiro, Rio de Janeiro, 2010.

Recebido: 23 jan. 2019

Aprovado: 17 set. 2019

DOI: $10.3895 / a c t i o . v 4 n 3.9399$

Como citar:

KARAT, M. T.; GIRALDI, P. M. A origem da vida: uma análise sobre a natureza da ciência em um vídeo educativo do YouTube. ACTIO, Curitiba, v. 4, n. 3, p. 178-193, set./dez. 2019. Disponível em:

$<$ https://periodicos.utfpr.edu.br/actio>. Acesso em: XXX

Correspondência:

Marinilde Tadeu Karat

Campus Universitário Trindade, $1^{\circ}$ andar, sala 103, Bloco B, CED. Caixa Postal: 476. Trindade - SC.

CEP:88040-900. Florianópolis, Santa Catarina, Brasil.

Direito autoral: Este artigo está licenciado sob os termos da Licença Creative Commons-Atribuição 4.0

Internacional.

(c) (i) 